\title{
Evaluation of wind energy investment with artificial neural networks
}

\author{
Hasan Huseyin Yildirim ${ }^{a}$ (D), Mehmet Yavuz $^{b^{*}}$ (i) \\ a Department of Banking and Finance, Balikesir University, Turkey \\ ${ }^{b}$ Department of Mathematics-Computer, Necmettin Erbakan University, Turkey \\ hhyildirim@balikesir.edu.tr,mehmetyavuz@erbakan.edu.tr
}

\section{ARTICLE INFO}

Article history:

Received: 31 January 2019

Accepted: 12 March 2019

Available Online: 17 March 2019

\section{Keywords:}

Energy

Wind energy

Forecasting

Energy investment evaluation

Artificial neural networks

AMS Classification 2010:

97R40, 97M30

\begin{abstract}
Countries aiming for sustainability in economic growth and development ensure the reliability of energy supplies. For countries to provide their energy needs uninterruptedly, it is important for domestic and renewable energy sources to be utilised. For this reason, the supply of reliable and sustainable energy has become an important issue that concerns and occupies mankind. Of the renewable energy sources, wind energy is a clean, reliable and inexhaustible source of energy with low operating costs. Turkey is a rich nation in terms of wind energy potential. Forecasting of investment efficiency is an important issue before and during the investment period in wind energy investment process because of high investment costs. It is aimed to forecast the wind energy products monthly with multilayer neural network approach in this study. For this aim a feed forward back propagation neural network model has been established. As a set of data, wind speed values 48 months (January 2012-December 2015) have been used. The training data set occurs from 36 monthly wind speed values (January 2012December 2014) and the test data set occurs from other values (January-December 2015). Analysis findings show that the trained Artificial Neural Networks (ANNs) have the ability of accurate prediction for the samples that are not used at training phase. The prediction errors for the wind energy plantation values are ranged between 0.00494-0.015035. Also the overall mean prediction error for this prediction is calculated as $0.004818(0.48 \%)$. In general, we can say that ANNs be able to estimate the aspect of wind energy plant productions.
\end{abstract}

(cc) $)$ EY

\section{Introduction}

Turkey is one of the developing countries, the economic change experienced in recent years has led to a rapid increase in demand in the energy sector, as it has in other sectors. While electricity production in Turkey showed an average annual increase of $3.6 \%$ between the years 1970 and 2000, electricity production increased annually by $8.9 \%$ on average between 2000 and 2017 years. In this regard, Turkey was one of the OECD countries in which energy demand increased the most rapidly. Electricity production in Turkey in 2017 increased by $5.6 \%$ to $294.8 \mathrm{GWh}$ compared with the previous year. $37 \%$ of this production was obtained from natural gas, $33 \%$ was obtained from coal, $20 \%$ from hydraulic energy, $6 \%$ from wind energy, $2 \%$ from geothermal energy and $2 \%$ from other sources [1]. In 2017, approximately $70 \%$ of electricity production came from fossil sources, namely coal, liquid fuels and natural gas, while about $28 \%$ was obtained from renewable energy sources. Between the years 1996 and 2017, energy imports made up an average of $20 \%$ of total annual imports. When evaluating Turkey's energy situation, the high percentage of the required energy is provided by imports has a negative effect on the balance of payments in a national economic sense. If Turkey's energy needs were obtained from domestic sources instead of imported sources, the foreign trade deficit would be reduced by approximately $48 \%$. Considering the overall picture of energy in Turkey in recent years, providing the required energy from domestic and renewable sources has become essential.

With regard to renewable energy potential, Turkey is a country with high potential for obtaining electricity production from wind and solar energy. According to the criteria specified, wind potential at a height of 50 metres on Turkey's wind atlas ranges from good to excellent, approaching 48 GW [2]. By July 2018, Turkey's wind-based energy capacity had reached 7 GW [3]. Turkey's wind-based power is about $15 \%$ of the energy potential that can be obtained from wind.

Within the scope of the 2015-2019 Strategic Plan

\footnotetext{
${ }^{*}$ Corresponding author
} 
prepared by the Ministry of Energy and Natural Resources, based on the diversification of resources in energy consumption with continuous, sustainable, environmentally friendly, good quality, reliable and low-cost energy for final consumers, the greatest possible utilisation of domestic and renewable energy sources was included among the main aims. In the 2015-2019 Strategic Plan, in the area of Energy and Natural Resources, common development needs such as good governance and stakeholder interaction, regional and international activity, technological research, development and innovation, and improvement of the investment environment are emphasised, while in the Energy field, security of supply and energy efficiency and saving are given priority. Moreover, in the field of Natural Resources, the subjects of security of supply of raw materials and efficient and effective use of raw materials are given attention. The subject of sustainability, which is regarded as an indispensable approach in the process of acquiring energy and natural resources for the economy and of their consumption, is designed not as a separate theme, but as a framework which covers all the themes [4].

The use of domestic and renewable energy sources ensures diversification of resources within the energy portfolio, thereby allowing important progress to be made in reducing dependence on foreign energy sources and developing an environment that provides security of energy supply [5].

In evaluating a wind energy project in an economic sense, a project estimate of the installation costs must be made. In the technical evaluation of a WPP investment, the subjects in which there is insufficient knowledge and uncertainties regarding the WPP investment are factors such as when it will be completed, when the installation of the investment will begin, when the installation period of the investment will be completed, future changes in prices of materials to be used in the investment and how long the supply of the turbine from the manufacturer will take. Businesses have to make decisions under the existence of uncertainties like these. It is important for companies to make decisions that are as correct as possible and that will gain the most profit.

This study is aimed to forecast the wind energy products monthly with multilayer neural network approach. For this aim a feed forward back propagation neural network model has been established. As a set of data, wind speed values 48 months (January 2012December 2015) have been used. The training data set occurs from 36 monthly wind speed values (January 2012-December 2014) and the test data set occurs from other values (January-December 2015).

\section{Literature review}

Wind power is the most common, widely applicable and productive renewable energy source. Studies about energy investments, wind speed predictions and renewable energy systems application with neural networks have been investigated especially about for a quarter century. In [6], Kalogirou et al. modeled the heat-up response of a solar steam generation plant and they were able to forecast pre-heat completion times within $3.9 \%$. This is considered very adequate and thus the neural network can be used effectively for this type of predictions. In another work [7], Kalogirou et al. estimated successfully the performance of a parabolic trough collector steam generation system by using ANN. Kemmoku et al. [8] developed a multi-stage neural network with back-propagation and by using it they forecasted daily insolation of next day. They also compared the mean errors of the insolation forecast obtained by single-stage and multi-stage neural networks. The results showed that the mean error by the single-stage was about $30 \%$ while by the multi-stage it was about $20 \%$. In [9], the authors developed a new Neural network model which helps to perform quickly and easily the estimations of office building energy consumption. Datta et al. [10] presented preliminary results on the estimation of electricity consumption with different independent input variables in a supermarket. Also they compared the prediction performance of one hidden layer-neural networks with the more traditional multiple regression techniques. Besides they founded the correlation coefficient as 0.95 with ANNs and 0.79 with the regression analysis. Dorvlo et al. [11] investigated a multilayer perceptron ANN model in order to estimate the solar radiation at any location in Oman. In other study [12], Aydinalp et al. developed a NN based energy consumption model for the Canadian residential sector. They presented the NN methodology used in developing the appliances, lighting, and space-cooling component of the model and the accuracy of its predictions. The study of More and Deo [13] employed the technique of neural networks in order to forecast daily, weekly as well as monthly wind speeds at two coastal locations in India. Öztopal [14] presented an artificial neural network (ANN) technique in order to determine weighting factors of surrounding stations necessary for the estimation of a pivot station. He compared the wind speed prediction results with measured values at a pivot station. Ermis et al. [15] developed a back-propagation feed forward ANN model in order to forecast world green energy consumption to the year 2050, and derived the consumption equations for different energy sources. Amrouche and Le Pivert [16] proposed a new neural network model for local forecasting of daily global solar radiation with satisfactory accuracy. Velazquez et al. [17] developed a new ANN model with back propagation by using Levenberg-Marquardt algorithm in order to determine influence of the input layer signals of ANNs on wind power estimation for a target site. They concluded from the study that the use of ANN models was helpful to estimate the wind energy potential of a site for which no long-term wind records are available. Zhao et al. [18] used in their ANN model the tan hyperbolic and sigmoid function and 
obtained that the error an average value of $16.47 \%$ in a whole month. The authors declared that the proposed system has a good wind power forecasting performance. Bigdeli et al. [19] showed that the hybrid ICA-neural network model is better than the others when prediction the wind power. Castellani et al. [20] obtained that the R2 between target test data and forecasted data is systematically higher using the pure NN approach. Qin et al. [21] demonstrated that the Cuckoo Search Optimization (CSO)-based Back Propagation Neural Network (BPNN) model can obtain higher quality interval forecasts for short-term wind speed forecasts. Wang et al. [22] presented a mediumterm wind speed forecasting performance analysis for three different sites in the Xinjiang region of China, utilizing daily wind speed data collected over a period of eight years. The experimental results of their study suggested that the hybrid models forecast the daily wind velocities with a higher degree of accuracy over the prediction horizon compared to the other models. The studies on the application of artificial neural networks to the wind energy plant and renewable energy sources are not limited to these. Detailed information can be found in [23] for other studies in this regard.

\section{Materials and methods}

In this section of the study, the main method related in this study will be described briefly, including ANN model developed, the algorithm and the activation functions used.

\subsection{Wind power plant information}

For this analyses of a WPP investment that maintains its activity in Balikesir province in the Southern Marmara region have been made by utilizing actual data. The data for thirty $3 \mathrm{MW}$ wind turbines in the installed plants of the wind power company have been used in the study.

\subsection{Application steps of research}

Under this heading, explanations were made about the implementation steps of the research. The application steps of the research consist of two steps, step 1 and step 2, as shown in Figure 1.

Step 1: The distribution of wind speeds of each turbine was determined by using the arena input analyzer. Then monthly wind speeds for 2015 were estimated by the MiniTab program with reference to the distributions between 2012-2014 for each wind turbine.

Figure 2 shows the 36-month distribution results of one of the thirty turbines WTG01. Based on these results, wind turbines of WTG01 coded for 2015 were estimated with minitab program.

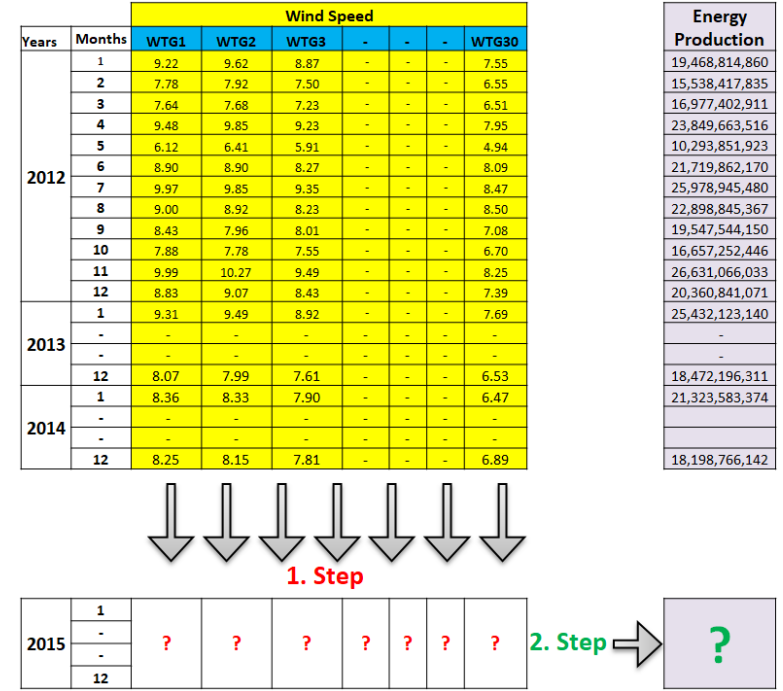

Figure 1. Research stages and framework

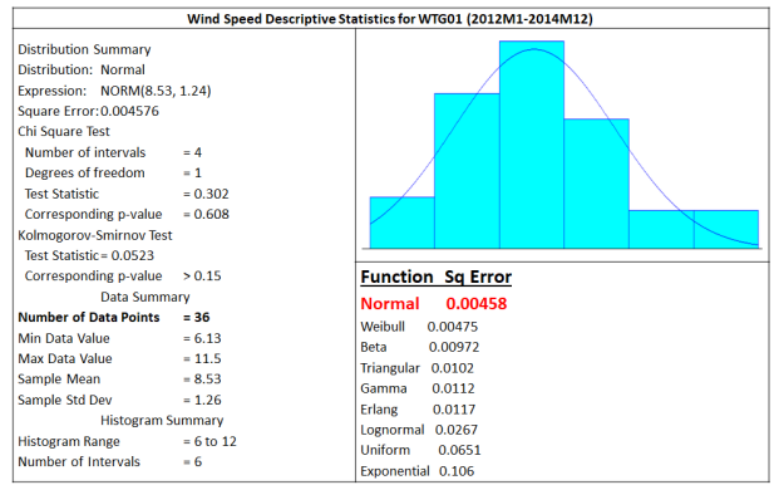

Figure 2. Arena input analyzer results of WTG1 coded turbine

Step 2: Artificial neural networks have been trained with production data realized in relation to wind speeds between 2012 and 2014. Monthly production for the year 2015 was estimated with reference to the trained network results.

\subsection{Proposed neural network model}

In this study it is aimed to forecast the wind energy products with multilayer neural network approach. For this aim a feed forward back propagation neural network model has been established. As a set of data, wind speed values 48 months (January 2012-December 2015) have been used.

The training data set occurs from 36 monthly wind speed values (January 2012-December 2015) and the test data set occurs from other values (JanuaryDecember 2015). The topology of the neural network is composed of 1 input layer, 3 hidden layers and 1 output layer. The number of neurons located in each layer 15, 20, 25 and 1, respectively. The topology of the network used in this study is given in Figure 3 [24]. 


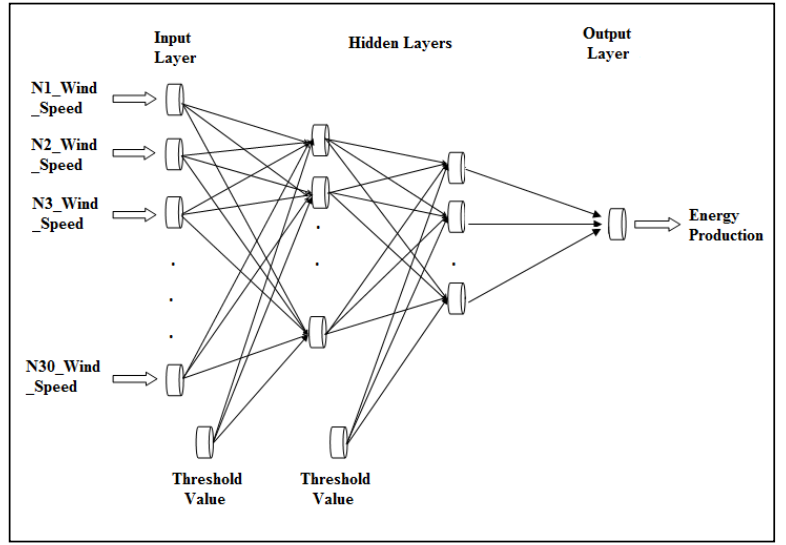

Figure 3. Network topology for the energy production prediction

In the layers purelin function, tangent hyperbolic function and tangent sigmoid function are used as activation function. The structures of purelin function and tangent hyperbolic function are presented in Figures 4(a) and 4(b).

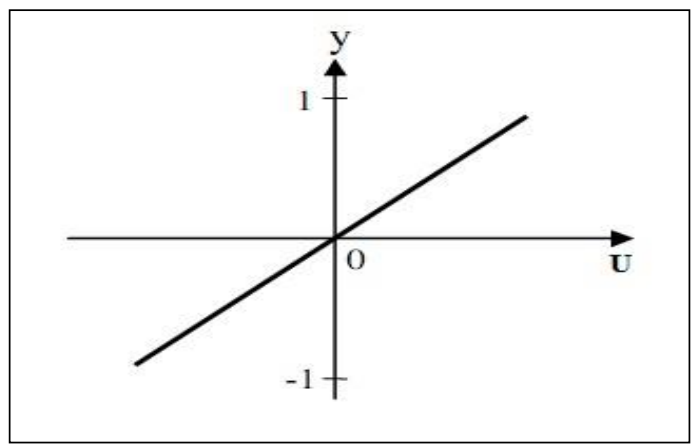

Figure 4(a). Purelin function

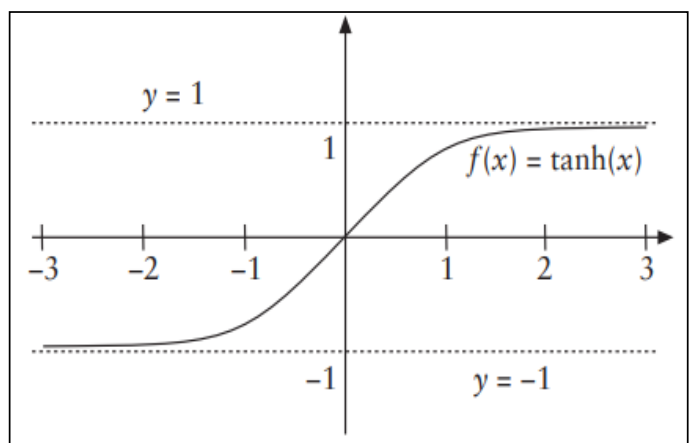

Figure 4(b). Tangent hyperbolic function

Purelin function can be defined in two different types such as $\omega_{1,2}=\sum_{i=1}^{n} x_{i} w_{i} \pm \theta$ and $y=f(\omega)=A \omega$, where $A$ is constant, $\theta$ is the threshold value and $\omega$ is the sum of the net input. Tangent hyperbolic function can be represented as $y=\tanh (\omega)=\frac{e^{\omega}-e^{-\omega}}{e^{\omega}+e^{-\omega}}[25]$.
The training of the ANN is performed by using Microsoft Visual Studio C\#.NET 2013. The normalized data, structure of ANNs used and mean square errors (mse) are presented for wind energy plantation prediction in Figure 5:

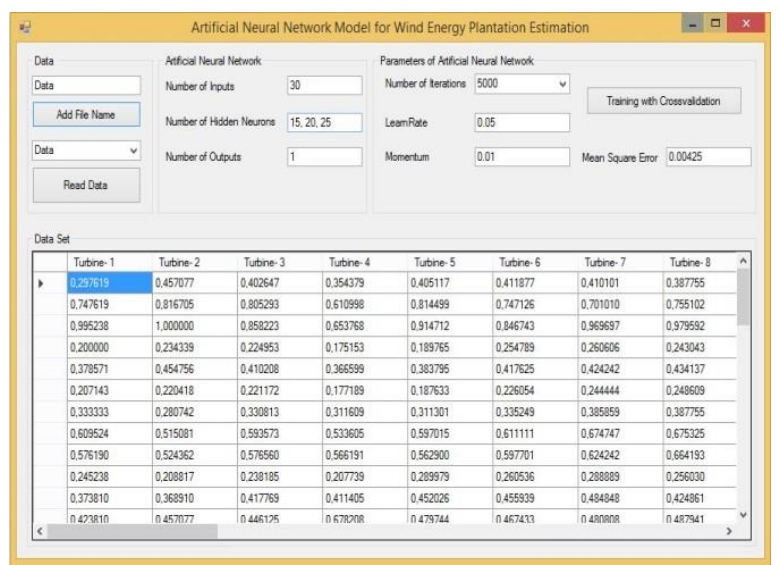

Figure 5. Structure of ANN used for wind energy plantation estimation

The pseudo-code for the given ANN is coded as [19]:

Define the input matrix as $\left(\mathrm{P}_{0}\right)$ and calculate its transpose as $(\mathrm{P})$

Define the output matrix as $\left(\mathrm{T}_{0}\right)$ and calculate its transpose as $(\mathrm{T})$

Determine the number of neurons of the input layer as (S0)

Determine the number of neurons of the hidden layers as (S1, S2, S3)

Determine the number of neurons of the output layer as (S4)

Construct the network topology and using the initialized weights between

-1 and 1

start to training by using the given code below:

$[\mathrm{Pn}, \min \mathrm{P}, \max \mathrm{P}, \mathrm{tn}, \min \mathrm{T}, \max \mathrm{T}]=\operatorname{premnmx}(\mathrm{P}, \mathrm{T})$;

$[\mathrm{Net}=\operatorname{newff}(\operatorname{minmax}(\mathrm{P}),[\mathrm{S} 0, \mathrm{~S} 1, \mathrm{~S} 2, \mathrm{~S} 3, \mathrm{~S} 4]$, 'traingd'];

net.trainParam.epochs $=\ldots$;

net.trainParam. goal $=\ldots$;

net.trainParam. show $=\ldots$;

net.trainParam. $\mathrm{mc}=\ldots$;

net.trainParam. $1 \mathrm{r}=\ldots$;

net.trainParam.1r_inc $=\ldots$;

net $=\operatorname{train}($ net $, P, T)$;

save training result.

\section{Analysis findings and discussions}

In this study the amount of energy produced between January 2012-December 2014 is used as the test values. Using the amount of energy production of 30 turbines, returns of these turbines are predicted with an ANN model that we developed. The test results are given in Table 1. 
Table 1. Comparing the energy production values and ANN findings

\begin{tabular}{|c|c|c|c|c|}
\hline Year & Months & $\begin{array}{c}(A) \\
\text { Amount of } \\
\text { energy } \\
\text { production } \\
(\text { kw) }\end{array}$ & $\begin{array}{c}\text { (B) } \\
\text { Predicted value of } \\
\text { energy with ANN }\end{array}$ & $\begin{array}{c}(\mathbf{C}=|\mathbf{A}-\mathbf{B}| / \mathbf{A}) \\
\text { Absolute Error }\end{array}$ \\
\hline \multirow{13}{*}{2015} & January & 17629023301 & 17576045381 & 0.003005 \\
\hline & February & 17582464880 & 17541452365 & 0.002333 \\
\hline & March & 14995980995 & 15221447853 & 0.015035 \\
\hline & April & 17609981947 & 17582614252 & 0.001554 \\
\hline & May & 14169262992 & 14142598562 & 0.001882 \\
\hline & June & 16036506273 & 15946251235 & 0.005628 \\
\hline & July & 22976464967 & 22965124526 & 0.000494 \\
\hline & August & 23972837201 & 24135689541 & 0.006793 \\
\hline & September & 15211951424 & 15304523688 & 0.006085 \\
\hline & October & 20874601700 & 20702569555 & 0.008241 \\
\hline & November & 18726339588 & 18736258954 & 0.000530 \\
\hline & December & 19920942346 & 20045258922 & 0.006240 \\
\hline & & & $\begin{array}{l}\text { Mean Absolute } \\
\text { Error }\end{array}$ & 0.004818 \\
\hline
\end{tabular}

The wind energy plantation prediction is performed for January 2012 and December 2014. The prediction errors between the observed values are given in $(\mathrm{C})$ column in Table-3. When these error values are examined the overall error rate for a long time period is lower than $0.5 \%$. These results show that the trained ANN has the ability of accurate prediction for the samples that is not used at training phase. The prediction errors for the wind energy plantation values are ranged between 0.000494-0.015035. Also the overall mean prediction error for this prediction is calculated as $0.004818(0.48 \%)$. In general, we can say that ANNs be able to estimate the aspect of wind energy plantation.

\section{Conclusion and recommendations}

Countries aiming for sustainability in economic growth and development ensure the reliability of energy supplies. For countries to provide their energy needs uninterruptedly, it is important for domestic and renewable energy sources to be utilised. Turkey, which is one of the developing countries, is the world's $17^{\text {th }}$ largest and Europe's $6^{\text {th }}$ largest economy. Together with its growing economy and increasing population, demand for energy in Turkey is rising rapidly. To meet this increasing energy need and to reduce foreign dependence on energy, the use of domestic and renewable energy sources must be increased. From this perspective, realistic targets for renewable energy sources should be set, and to reach these targets, the barriers preventing investments should be lifted.

When its potential for renewable energy sources is assessed, Turkey is a rich country. Before companies make an investment in a renewable energy area, it is important that they undertake technical and economic feasibility studies of the investment. A pre-feasibility study will form a reference for the practicability of the investment. Following the pre-feasibility study, highproductivity renewable energy investments are important for providers of liability in terms of repayment of the credit they are to provide.

In this respect, it is very important to estimate the future energy generation for those who invest in wind energy.
It is aimed to forecast the wind energy products monthly with multilayer neural network approach in this paper. For this aim a feed forward back propagation neural network model has been established. As a set of data, wind speed values 48 months (January 2012December 2015) have been used. The training data set occurs from 36 monthly wind speed values (January 2012-December 2014) and the test data set occurs from other values (January-December 2015). Analysis findings show that the trained Artificial Neural Networks (ANNs) has the ability of accurate prediction for the samples that is not used at training phase. The prediction errors for the wind energy plantation values are ranged between 0.00494-0.015035. Also the overall mean prediction error for this prediction is calculated as $0.004818(0.48 \%)$. In general, we can say that ANNs be able to estimate the aspect of wind energy plant productions.

The results obtained suggest that ANN model can be used quite successfully in this area and it can forecast correctly the value for wind power with an accuracy margin error even for unknown samples.

\section{References}

[1] http://www.enerji.gov.tr [Accessed 11 October 2018].

[2] Develi, A. \& Kaynak, S. (2012). Energy Economics, Frankfurt am Main, ISBN 3631633335, DEU:Peter Lang AG.

[3] Turkish Wind Energy Association, Turkish Wind Statistic Report 2018 July, https://www.tureb.com. tr/yayinlar/turkiye-ruzgar-enerjisi-istatistik-raporutemmuz-2018.

[4] Ministry of Energy and Natural Resources (2014). 2015-2019 Strategy Plan, http://sp.enerji.gov.tr/ ETKB_2015_2019_Stratejik_Plani.pdf, 26.

[5] Bahgat, G. (2006). Europe's energy security: challanges and opportunities, International Affairs, 82(5), 961-975.

[6] Kalogirou, S.A., Neocleous, C.C., \& Schizas, C.N. (1996). Artificial neural networks in modelling the heat-up response of a solar steam generation plant, Proceedings of the International Conference EANN, 1-4.

[7] Kalogirou, S.A., Neocleous, C.C., \& Schizas, C.N. (1997). Artificial neural networks for the estimation of the performance of a parabolic trough collector steam generation system, Proceedings of the International Conference EANN, 227-232.

[8] Kemmoku, Y., Orita, S., Nakagawa, S., \& Sakakibara, T. (1999). Daily insolation forecasting using a multistage neural network, Solar Energy, 66(3), 193-199.

[9] Kajl, S., Roberge, M.A., Lamarche, L., \& Malinowski, P. (1997). Evaluation of building energy consumption based on fuzzy logic and neural networks applications, Proceedings of the International Conference CLIMA 2000, 264-274. 
[10] Datta, D., Tassou, S.A., \& Marriott, D. (2000). Application of neural networks for the prediction of the energy consumption in a supermarket, Proceedings of the International Conference CLIMA 2000, 98-107.

[11] Dorvlo, A.S., Jervase, J.A., \& Al-Lawati, A. (2002). Solar radiation estimation using artificial neural networks, Applied Energy, 71(4), 307-319.

[12] Aydinalp, M., Ugursal, V.I., \& Fung, A.S. (2002). Modeling of the Appliance, Lighting, and SpaceCooling Energy Consumptions in the Residential Sector Using Neural Networks, Applied Energy, 71(2), 87-110.

[13] More, A., \& Deo M. (2003). Forecasting Wind with Neural Networks, Marine Structures, 16(1), 35-49.

[14] Öztopal, A. (2006). Artificial Neural Network Approach to Spatial Estimation of Wind Velocity Data, Energy Conversion and Management, 47(4), 395-406.

[15] Ermis, K., Midilli, A., Dincer, I., \& Rosen, M.A (2007). Artificial neural network analysis of world green energy use. Energy Policy, 35(3), 1731-1743.

[16] Amrouche, B., \& Le Pivert, X. (2014). Artificial neural network based daily local forecasting for global solar radiation. Applied Energy, 130, 333341.

[17] Velázquez, S., Carta, J. A., \& Matías, J. M. (2011). Influence of the input layer signals of ANNs on wind power estimation for a target site: A case study. Renewable and Sustainable Energy Reviews, 15(3), 1556-1566.

[18] Zhao, P., Wang, J., Xia, J., Dai, Y., Sheng, Y., \& Yue, J. (2012). Performance evaluation and accuracy enhancement of a day-ahead wind power forecasting system in China. Renewable Energy, 43, 234-241.

[19] Bigdeli, N., Afshar, K., Gazafroudi, A.S., \& Ramandi, M.Y. (2013). A comparative study of optimal hybrid methods for wind power prediction in wind farm of Alberta, Canada. Renewable and sustainable energy reviews, 27, 20-29.

[20] Castellani, F., Burlando, M., Taghizadeh, S., Astolfi, D., \& Piccioni, E. (2014). Wind energy forecast in complex sites with a hybrid neural network and CFD based method. Energy Procedia, 45, 188-197.

[21] Qin, S., Liu, F., Wang, J., \& Song, Y. (2015). Interval forecasts of a novelty hybrid model for wind speeds. Energy Reports, 1, 8-16.

[22] Wang, J., Qin, S., Zhou, Q., \& Jiang, H. (2015). Medium-term wind speeds forecasting utilizing hybrid models for three different sites in Xinjiang, China. Renewable Energy, 76, 91-101.

[23] Ata, R. (2015). Artificial Neural Networks Applications in Wind Energy Systems: A Review, Renewable and Sustainable Energy Reviews, 49, 534-562.

[24] Sakarya, S., Yavuz, M., Karaoglan, A.D., \& Özdemir, N. (2015). Stock market index prediction with neural network during financial crises: a review on BIST-100. Financial Risk and Management Reviews, 1(2), 53-67.

[25] Yavuz, M., Sakarya, S., \& Özdemir, N. (2015). Yapay Sinir Ağları ile Risk-Getiri Tahmini ve Portföy Analizi, Ömer Halisdemir Üniversitesi İktisadi ve İdari Bilimler Fakültesi Dergisi, 8(4), 87107.

Hasan Huseyin Yildirim received his Master's Degree (2011) in Finance from Marmara University and obtained a PhD Degree (2016) from Istanbul University. Mr. Yildirim is Assist. Prof. in the Burhaniye School of Applied Sciences at Balikesir University. His research interests include the economy, finance and banking sector and renewable energy investments.

Mehmet Yavuz is an Assistant Professor at the Department of Mathematics-Computer, Faculty of Science, Necmettin Erbakan University, Turkey. He received his B.Sc. (2009) degree from Department of Mathematics, Bulent Ecevit University, Turkey. He received his M.Sc. (2012) and Ph.D. (2016) degrees from Applied Mathematics, Balikesir University, Turkey. His research areas include fractional calculus, differential equations, artificial intelligence and financial mathematics.

An International Journal of Optimization and Control: Theories \& Applications (http://ijocta.balikesir.edu.tr)

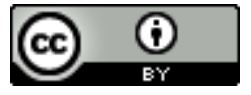

This work is licensed under a Creative Commons Attribution 4.0 International License. The authors retain ownership of the copyright for their article, but they allow anyone to download, reuse, reprint, modify, distribute, and/or copy articles in IJOCTA, so long as the original authors and source are credited. To see the complete license contents, please visit http://creativecommons.org/licenses/by/4.0/. 